\title{
Understanding the global strategy for disaster risk reduction
}

Monika Berg, Environmental Sociology section, Örebro University, Sweden

Veronica De Majo, Dalarna University and Örebro University, Sweden

This is an Accepted Manuscript of an article published in Risk, Hazards \& Crisis in Public

Policy 2017, 8:2, pp. 147-167, available online:

http://onlinelibrary.wiley.com/doi/10.1002/rhc3.12110/abstract. (Published 13 Jun 2017)

\begin{abstract}
Disasters are a growing international concern that has spurred the development of political strategies and policies from international to local levels. This paper analyzes how disasters are constructed as a policy problem within the UN global strategy for disaster risk reduction. Building on a social constructivist view of policy problems, we analyze how disasters and disaster risks are being represented through these global policies, while we also pay attention to what this representation excludes and deemphasizes. We show that the UN strategy is mostly concerned with adjusting or adapting societies to hazards, and managing risks, rather than addressing the social processes that render people vulnerable to those hazards. The predominant concern with technological and managerial solutions eclipses the need for changes in the social structures that create disaster risks. We argue that the understanding of disasters represented in the UN strategy supports an emerging holistic paradigm. However, we also argue that the holism it represents is limited rather than radical. By making visible what is excluded or not properly problematized in this representation, we point to the complexity of the task and show where its limitations lie.
\end{abstract}




\section{Introduction}

Disasters are a growing international concern, leading to the development of political strategies and policies from international to local levels. Within this policy field, as well as in related research, the focus has primarily been on action in terms of possible and suitable interventions, such as how to increase preparedness, to anticipate disasters and lessen their consequences. The policy field of disaster risk reduction has come to be dominated by a technical rationality, where central concepts such as resilience, coming from the natural sciences, have contributed to an image of neutrality (Pizzo, 2015). As a consequence, the constitution of the policy problem tends to be treated as objectively observable, rather than socially constructed. However, even technical discourses entail value judgments and ideological dimensions, which the image of neutrality tends to obscure (Hajer, 1995, Fischer, 2003).

If we see policies as constituting competing interpretations and representations of political issues, other analytical questions become relevant to clarify the contingencies and consequences of a particular representation of a problem (Bacchi, 2008; Yanow, 1996). Analyzing how a particular problem is constituted through its representation in policy and through proposed action offers a way to see beyond the dominant understanding of the issue. It invokes consideration of which issues are left unaddressed or are de-emphasized as a consequence of the particular way in which the issue is represented (Bacchi, 2008). By identifying how a particular policy problem is being represented, one may also illustrate where responsibility is directed, as well as how responsibility may be transferred by changing how the problem is represented (Stone, 2012, Chapter 9). Thus, by analyzing the problematization of disasters and how it has been constructed as a policy problem, it is possible to identify the value dimensions implicit in technicalities and show that there are alternative courses of action (Hajer, 1995, p. 291).

Regarding global disaster policy, the international community has agreed upon two major frameworks, the Hyogo Framework for Action 2005-2015: Building the Resilience of Nations and Communities to Disasters (HFA), and the Sendai Framework for Disaster Risk Reduction (SFDRR). The constitution of these international frameworks is not only shaped by global norms; they can also be considered expressions of global norms regarding this subject. However, there is currently limited research that problematizes the global strategy for disaster risk reduction. Some critical studies have been done (Konoorayar, 2006; Olowu, 2010; Hollis, 
2014; Kelman, 2015; Weichselgartner \& Pigeon, 2015; Pearson \& Pelling, 2015); however, none focus on the problematization of disasters expressed in these policies. The vast majority of existing studies that address these policies are more traditional in scope, not coming from critical traditions. They deal with the way in which concepts such as vulnerability (Birkmann, 2006; Birkmann \& Wisner, 2006; Vink \& Takeuchi, 2013) and resilience (Djalante \& Thomalla, 2011; Matsuoka \& Shaw, 2011) are defined, operationalized, and measured in one or both of the UN frameworks, as well as the extent to which they have been implemented at national and local levels, underlining progress and challenges (e.g., Stanganelli, 2008; Matsuoka et al., 2009; Olowu, 2010; Djalante et al., 2012; Matsuoka \& Shaw, 2012; Enia, 2013; Manyena et al., 2013; Jensen et al., 2015). Thus, there is a knowledge gap regarding how disasters are represented and problematized within these frameworks, as well as what understanding of disasters these policies reproduce.

The aim of this paper is to analyze how disasters are represented as a policy problem within the UN global strategy for disaster risk reduction. Building on a social constructivist view of policy problems, we address this aim by answering two analytical questions. What are the causal assumptions that underlie this representation, in terms of appointed space for action and responsible actors? And what is excluded from this representation? Since the process of problematization is historically contingent (Bacchi, 2012), we will turn to the research literature on disasters and disaster risk reduction to identify the dominant problematizations of disasters over time. From that we will elaborate a set of causal logics (Stone, 2012) that have shaped the understanding of disasters as a policy problem, giving partly different meanings to disasters, appointing different relevant actors, as well as different space for action. These logics will then serve as heuristics in our analysis of the documents.

The paper comprises six sections, whereof this introduction is the first. The second section accounts for our social constructivist view on policy formation and what it means to analyze problematizations. We argue that causalities play a crucial role in problem representations, wherefore we turn to Stone's (2012) typology of causal theories, in order to develop our analytical framework further. In the third section we apply our theoretical approach on the academic debates of disaster risk reduction to illustrate how the understanding of disasters has evolved over time. This section outlines three different "paradigms" that will serve as comparative reference points in our analysis of silenced perspectives within the current UN strategy. The forth section introduces the two UN frameworks (HFA and SFDRR) and how they have been analyzed, while the fifth section contains the analysis. We address each of the 
two frameworks, and close with an account for de-emphasized or excluded perspectives. In the last section we highlight the main conclusions of the analysis and engage in a discussion regarding the implications of our findings.

\section{Analyzing problematizations}

Taking a social constructivist view on policy implies that policy is not seen as a solution to conditions and problems existing “out there,” but that the policy creates and shapes problems to a large extent. Thus, while policies aim to address problems, they also produce or constitute those problems, with particular meanings and effects (Bacchi, 2015, pp. 2, 5). The focus of analysis is therefore not on the problem, but on problematizations (Bacchi, 2000). Problematization can be conceptualized as the "thinking" that comes to constitute something as an object of thought and as a policy problem. The aim of studying problematizations is to illuminate "the terms of reference within which an issue is cast" (Bacchi, 2012, p. 1). Foucault (quoted in Bacchi, 2012, p. 4) writes

\section{Problematization doesn't mean the representation of a pre-existing object, nor the creation through discourse of an object that doesn't exist. It is the set of discursive and non-discursive practices that makes something enter into the play of the true and the false and constitutes it an object of thought}

Bacchi's (2008, 2012) approach and method of analysis is strongly influenced by Foucault and what he refers to as "thinking problematically." The aim is not to arrive at a correct response, but to examine how a particular phenomenon (in our case, disasters) is understood, classified, and regulated at specific times in specific contexts, thus, how it is constituted as a problem. For followers of Foucault a crucial ambition is to render objects with fixed meanings fragile (Bacchi, 2012, pp. 1-2), as a means to challenge current power structures. While Foucault explored problematizations by investigating social practices, Bacchi (2008) has developed this approach to bear on the field of policy studies. She sees public policies and policy proposals as prescriptive texts. The practices proposed by a policy rely on specific problematizations (Bacchi 2012), wherefore policies provide fruitful entry points for identifying problematizations. Bacchi (2012) argues that it is "possible to take any policy proposal and to 'work backwards' to deduce how it produces a problem” (p. 4). 
Neither Bacchi nor Foucault goes further than establishing this analytical perspective and guiding analytical questions. To more systematically analyze how the problem is represented, and what shifts in the representation imply, we therefore build on Stone (2012) and her typology of causal theories (see Table 1). Causal theories are a crucial component for understanding problems (see, e.g., Schön \& Rein, 1994; Hajer \& Laws, 2006). The dominant understanding of problems is that they can only be properly defined and solved after their cause(s) have been established. This understanding rests on the particular conception of cause, that any problem has deep and primary causes that can be identified through careful research (Stone, 2012, p. 206). Within the political sphere, however, identifying causes has another meaning, that of appointing responsibility and blame, oppressors and victims. Since policy problems are complex, they are often subject to continuous debate regarding underlying causal processes. Through these meaning-making processes the political and the scientific fields become intrinsically related, or as Jasanoff (2004) puts it, they are co-produced.

Table 1. Types of causal theories (Stone, 2012, p. 208)

\begin{tabular}{|c|c|c|}
\hline \multirow[b]{2}{*}{ Actions } & \multicolumn{2}{|l|}{ Consequences } \\
\hline & Intended & Unintended \\
\hline Unguided & $\begin{array}{l}\text { MECHANICAL CAUSE } \\
\cdot \quad \text { Machines that cause harm } \\
\cdot \quad \text { Rigid bureaucratic } \\
\text { routines }\end{array}$ & $\begin{array}{l}\text { ACCIDENTAL CAUSE } \\
\text { · } \\
\text {. } \\
\text { Fatural disaster } \\
\text {. } \\
\text { Bad luck }\end{array}$ \\
\hline Guided & 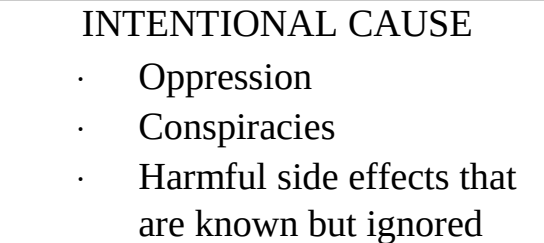 & $\begin{array}{ll}\text { INADVERTENT CAUSE } \\
\cdot \quad \text { Unanticipated harmful } \\
\text { side effects of policy } \\
\cdot \quad \text { Avoidable ignorance } \\
\text {. } & \text { Carelessness }\end{array}$ \\
\hline
\end{tabular}

Inherent in the suggestions for how to reduce a problem, and in particular, understandings of what causes it, are assumptions of what ought to be different as well as what is not up for change (Rittel \& Webber, 1973, p. 165, authors’ italicization). The way disasters are problematized implies where responsibility and space for action are identified. In the upper right box of Table 1 are accidental causes. Typical accidental causes are those adhering to the realm of nature, such as natural hazards, but also such as we ascribe to the realm of fate and bad luck. There is no intentional action involved, only occurrences. Thus, there is no blame or responsibility to assign, nor is there any space to act to prevent them. Other causes are 
inadvertent causes, such as harmful side effects of well-intentioned policy. This category also includes soft versions of "blaming the victim"; for example, if groups that are subject to high disaster risks only knew better how their actions affected risks, the consequences of disasters could be avoided. Thus, information campaigns or education directed towards the vulnerable become a crucial activity. A more direct way of blaming the victims is to depict them as careless or reckless, which would fall under intentional cause, through their negligence or thoughtlessness concerning harmful side effects. Such a problematization tends to ignore structural power relations. Causes that are intended, guided or not, are seldom directly applicable to natural disasters; however, they can form part of a more complex causal story in relation to risk reduction and mitigation. Policy problems of a "wicked” character require more complex models of cause, which involve a combination of these categories. Thus, a crucial task is to analyze how different causal logics are combined, and with what effects. It is central to note that, in relation to responsibility and control, complex system stories may come to function as accidental or natural causes, since no actor can exert control or even have some kind of overview over the whole system (Stone, 2012, Ch 9).

Stone's typology will guide us in the analysis of the causal assumptions represented in the frameworks, including the responsibilities and space for action that they appoint. But how may excluded perspectives be identified? When having identified the causal understandings of a particular problem representation and presented these as propositions, rather than truths, the problematization is opened up for reconstruction (Yanow, 1992, p. 418). It is possible to rephrase the problem and thereby point to silence in problematizations (Bacchi, 2000, p. 5). A practical way of doing this is through comparison (Dahl, 2012). Since our focus is on the international level, a possible point of comparison is in time, based on how the understanding of disasters has evolved. This exercise may not, and does not attempt to, be exhaustive, since it is confined to existing or earlier representations. However, it may serve to unlock dominant assumptions. In the next section we therefore turn to the research literature on disasters and disaster risk reduction to identify dominant problematizations of disasters over time.

\section{The understanding of disasters as reflected in the academic literature}

The understanding of disasters has evolved through the years, being originally the belief that they were something supernatural, later on defined as something caused by nature, and finally, considered a consequence of human behavior (cf. Quarantelli, 2000; Furedi, 2007; 
Dodds, 2015). In this section we outline thee different paradigm in the understanding of disasters as a policy problem (summarized in Table 2).

Before the 1980s the focus of global disaster management was on humanitarian aid. The dominant understanding of disasters within the environment and disaster literature was shaped by the hazard paradigm, as it has been called, in which natural hazards were defined as damaging elements in the physical environment caused by forces extraneous to humans (Burton \& Kates, 1964, p. 84), with uncontrollable dimensions (Frampton et al., 2000). Hazards were seen as rare and extreme events with the consequence of exceeding humans' ability to resist (Gaillard, 2010, p. 221). In this sense, disasters were considered to be the result of physical events, and as something apart from normal social and cultural processes (Hannigan, 2012). As they were characterized as having an accidental cause, there was no responsibility to be assigned, and the space for action was limited. Due to this understanding of the problem, researchers in social sciences put the focus on the social consequences of disasters, such as the way that people and societies perceive the danger, and the way that they respond to and adjust after these extreme events. At the same time, this conceptualization of the problem left aside factors in the socioeconomic environment, factors that interact with the flood or storm to shape the social outcome. Actions taken were generally confined to postdisaster short-term measures, mainly based on humanitarian and relief aid and grounded in the moral obligation to those in need (Konoorayad, 2006; Hollis, 2014). Such measures represented only a temporary solution to a crisis, most likely recreating conditions of vulnerability (McEntire, 1998; Comfort et al., 1999).

Starting in the 1970s, another approach came to influence the understanding of disasters and their consequences, especially in the 1980s, namely, what is called the vulnerability paradigm. This perspective took its starting point in the developing world and was fostered by development policies. It put people's vulnerability in focus, which can vary in time and space and is determined by hazard-independent structural constraints: social, cultural, economic, and political (cf. Wisner et al., 2004; Gaillard, 2007). Disasters were depicted as a function of development (Collins, 2009), in terms of "social orders, human-environment relations, and historical structural processes” (Oliver-Smith, 1999, p. 22). This understanding implies that a separation was made between natural hazards and disasters, where the vulnerability factors determine the consequences of a hazardous event. The focus for action came to be directed at reducing vulnerability, and thereby, disasters, rather than avoiding hazards or mitigating their consequences. By taking the vulnerability of the modern world as a starting point (Oliver- 
Smith, 1996; Furedi, 2007), disasters came to be seen and addressed as ongoing problems instead of occasional crises (Comfort et. al., 1999, p. 42). This representation of disasters enlarged the realm of their causes, in particular, to include not only inadvertent causes such as avoidable ignorance or structurally imposed carelessness (both in relation to local practices in developing countries) but also economical structures that may be interpreted as harmful side effects of policy (anticipated or not) or even as structural oppression. Thus, intentional causes came into the picture and, with that, an analysis of responsibilities and blame. This representation of the problem thereby both enlarged the space for action (cf. Collins, 2009), to involve large-scale structural (paradigmatic) changes, and added an explicitly political dimension to it, in terms of global inequality structures.

An evolving way to view disasters is often referred to as "holistic" (McEntire, 2001; Palliyaguru et al., 2014). We have chosen to call this view the holistic paradigm, though it is still an open question whether it could be regarded as such, and the extent to which it is holistic. This view emphasizes a multicausal understanding of disasters. The problem in focus is no longer disasters, exclusively, but disaster risks. This means moving from a focus on occasional events and crises towards the more constant state of being at risk, allowing the possibility of managing risks in order to mitigate disasters. The emphasis on disaster risks has led to the rise of a more proactive approach to disaster management, enhancing the scope for action to encompass measures taken before, during, and after disasters. Consequently, while relief aid is still a central component in the response phase, focus is put on mitigation, preparedness for an effective response, and sustainable recovery. This has been pictured as a shift away from a "response-mentality alone” (McEntire, 2001, p. 193), towards activities aiming to enhance knowledge and capacities to anticipate disasters and lessen their adverse consequences, as well as to respond effectively and recover in an improved manner. The shift towards proactivity has implied a focus on managing risks, giving a central role to technical solutions in order to identify hazards in advance, as, for example, risk assessments and early warning systems (cf. McEntire, 1998). However, it is crucial to note that this shift towards risk management also means a shift away from the vulnerability paradigm and its emphasis on structural inequalities and systemic change at an international level.

According to the holistic paradigm, disaster risk is seen as a complex causal system in which both the hazard and the vulnerabilities may have various causes. The focus has shifted from natural hazards to "a triggering agent” that can come not only from the natural environment but also from human activity (Geis, 2000; McEntire, 2001; McEntire et al., 2002). Both 
inadvertent and intended causes may form part of a combined causal story. The trigger may, in addition to natural hazards, be oil spill, pollution, or acid rain, and even terror attacks are at times included. Vulnerabilities are related to human activity, and particularly, the interaction between physical, built, technological, and social systems (Hoffman \& Oliver-Smith, 1999; McEntire, 2001; Palliyaguru et al., 2014). It is depicted as a dynamic component that, if not addressed, tends to increase over time (cf. McEntire, 2001). In relation to the vulnerability paradigm, the emphasis has shifted from factors related to complex social vulnerability structures, for example, those produced by global interdependence, to localized factors such as technical structures, built environments, or cultivated lands. This implies more tangible and localized remedies, where technical solutions, such as innovative communications for raising awareness provide the answers, rather than structural social change.

The causal logic represented in this paradigm is that of a complex system, where multiple causal theories are combined. The representation of a complex causal system takes on the function of a natural cause. Due to its complexity, responsibilities are dispersed and become elusive, and control seems far-fetched (Stone, 2012). This also means that blame is obscured, as opposed to in the vulnerability paradigm. It should be noted that the representation of the problem has come to emphasize the possibility of control through physical, technical, and managerial solutions. However, the political dimension has decreased, and there is no blame assigned.

The most recent change in the way disasters are problematized, which we see as a part of the holistic paradigm, is related to the interconnection between disasters and climate change and the view that disaster risk reduction should be actively included in environmental strategies, and vice versa. It has been argued that these policy fields have taken separate pathways due to central differences in the understanding of the nature, scope, and impact of the problem they address, as well as in the time frames of policies and strategies (cf. O’Brien et al., 2006; Schipper \& Pelling, 2006; Thomalla et al., 2006; Botzen \& Van den Bergh, 2009; Mercer, 2010). However, the two policy fields have started to overlap, which, for one thing, has to do with the dispersed duality between society and nature (Lövbrand et al., 2015). It is increasingly recognized that nature and society are not to be regarded as dualities, but that focus should be put instead on their interrelations (see, e.g., Latour, 2004; Gregory et al., 2009). Environmental phenomena can no longer be considered as pure accidental causes (Stone, 2012, p. 218). The notion of global warming and other environmental effects of social systems have given them a new meaning and made them (at least partly) understood as 
inadvertent causes. This shift in understanding (once again) enlarges the potential space for action, as well as the political dimension of disasters, to include the mechanisms, as well as the structure, of the global economic system. However, the degree to which the social and economic structures will be integrated within this field also depends on developments in the environmental discourse, where this is an emerging discussion.

Table 2 summarizes the characteristics of these shifting representations of disasters. These different "paradigms," as they are generally referred to, should not be seen as mutually exclusive. They overlap each other in policy as well as in research. The table highlights the specific characteristics and what is particularly emphasized in each of the perspectives.

Table 2. Different representations of disasters as a policy problem

\begin{tabular}{|l|l|l|l|l|l|}
\hline & Problem & Type of cause & Relevant actors & $\begin{array}{l}\text { Emphasized } \\
\text { remedies }\end{array}$ & $\begin{array}{l}\text { Dominating } \\
\text { disciplines }\end{array}$ \\
\hline $\begin{array}{l}\text { Hazards } \\
\text { paradigm }\end{array}$ & $\begin{array}{l}\text { The hazardous } \\
\text { event }\end{array}$ & $\begin{array}{l}\text { Accidental cause, } \\
\text { fate, or natural } \\
\text { hazards }\end{array}$ & $\begin{array}{l}\text { Those with ability } \\
\text { to help }\end{array}$ & Relief aid & Natural sciences \\
\hline $\begin{array}{l}\text { Vulnerability } \\
\text { paradigm }\end{array}$ & $\begin{array}{l}\text { Social } \\
\text { vulnerability }\end{array}$ & $\begin{array}{l}\text { Accidental in } \\
\text { combination with } \\
\text { inadvertent cause }\end{array}$ & $\begin{array}{l}\text { The developed } \\
\text { countries }\end{array}$ & $\begin{array}{l}\text { Information and } \\
\text { education. } \\
\text { International }\end{array}$ & $\begin{array}{l}\text { Development } \\
\text { studies }\end{array}$ \\
\hline $\begin{array}{l}\text { Holistic } \\
\text { paradigm }\end{array}$ & $\begin{array}{l}\text { Disaster risk } \\
\text { The interaction } \\
\text { between } \\
\text { physical, built, } \\
\text { technological, } \\
\text { and social } \\
\text { systems }\end{array}$ & $\begin{array}{l}\text { Complex system, } \\
\text { and thereby taking } \\
\text { characteristics of an } \\
\text { accidental cause. }\end{array}$ & $\begin{array}{l}\text { A broad set of local } \\
\text { actors, e.g., public- } \\
\text { private networks, } \\
\text { scientific } \\
\text { communities, civil } \\
\text { society, and the } \\
\text { business sector }\end{array}$ & $\begin{array}{l}\text { Knowledge and } \\
\text { technical } \\
\text { development (and } \\
\text { their } \\
\text { implementation) } \\
\text { Sustainable }\end{array}$ & $\begin{array}{l}\text { Cross-disciplinary } \\
\text { Disaster studies, } \\
\text { social sciences, } \\
\text { natural sciences, } \\
\text { urban planning, } \\
\text { etc }\end{array}$ \\
\hline
\end{tabular}

\section{Research design and materials}

In this paper we analyze the UN's International Strategy for Disaster Risk Reduction. Our empirical material encompasses two internationally-agreed-upon frameworks, the particular character of which has consequences for their analysis. We will therefore start this section by presenting them, the process behind their agreement, and their particular character as texts. Thereafter, we will account for how we have systematically analyzed these documents.

The first document is the Hyogo Framework for Action, which is considered to be the first international agreement on the necessity to systematically incorporate disaster risk reduction 
efforts into policies at all levels (see e.g. Collins, 2009, p. 40; Djalante et al., 2012, p. 781; Hannigan, 2012, p. 18). The second, the Sendai Framework for Disaster Risk Reduction, is the HFA's successor, which seeks to be a broader and more inclusive approach and will represent the global strategy for disaster risk reduction until 2030. By analyzing both frameworks, we may identify continuities and changes in the policy formation process.

The HFA is mainly the result of state-driven intergovernmental negotiations, supported by international and regional administrative organizations. It was finally discussed and agreed upon in the Second World Conference on Disaster Reduction in Kobe, Japan, in 2005. The SFDRR was shaped by different mechanisms, starting with an online dialogue in 2011, and followed by a multistakeholder consultation process in 2012-2013 (i.e., global, regional, national, thematic, and stakeholder). The proposed elements for the new framework were later negotiated in interstate meetings. The framework was ultimately discussed and agreed upon in the Third Conference on Disaster Risk Reduction held also in Japan, this time in Sendai. Both documents are condensed and technical in their character, defining expected outcomes, strategic goals, and (to some extent) handling strategies. While the HFA is a result-based plan, the SFDRR is designed to be more action-oriented and includes global targets. Their length is 25 pages and 37 pages, respectively. We have summarized the main features of the documents in Appendix 1.

Based on our theoretical approach we have three interrelated analytical questions: (1) What kind of problem are disasters represented to be within these frameworks? (2) What is the effect of the causal assumptions that underlie this representation, in terms of appointed space for action and responsible actors? (3) What is excluded from the representation? The process behind these strategies, and their dense and technical character, affects the way that they can be analyzed. The political process behind these documents makes them inclusive to perspectives, if only mentioned occasionally, in passing, or without further definition or development of their implications for policy. When addressing our analytical questions, we therefore focus on the dominant (recurring) representations within the frameworks. Concerning our first analytical question, the frameworks do not include an elaboration or discussion of disasters as policy problems. Causal logics ascribed to disasters were identified through the definition of 'disaster risks', including the causal understandings of hazards and vulnerabilities that were expressed in the documents. However, the analytical questions are interrelated. Since problem definition may be embedded in or implied by proposed solutions (Rittel \& Webber, 1973), we see the strategies and recommended measures as part of the 
representation of the problem, meaning that it is crucial to identify what kind of problem they imply (cf. Bacchi, 2012). This counts also for the appointed actors, which has implications for how the problem is being represented. By drawing on the causal theories presented in table 1, we discuss the implications of the dominant problem representations (within the frameworks) in terms of space for action as well as ascribed responsibilities.

For the last analytical question, which concerns silences or de-emphasized aspects of the frameworks, we use the three paradigms summarized in Table 2. The paradigms and their four dimensions (problem representation, type of cause, relevant actors, and emphasized remedies) serve as reference points, making it possible to identify alternative representations that are missing, as well as to identify the logics of the dominant representation of the problem within the frameworks.

\section{The global strategy for disaster risk reduction}

In this section we present the analyses of the UN frameworks for disaster risk reduction, and how disasters are being represented as a policy problem. First, we point to the effects of the current representation in terms of appointed space for action as well as responsible actors within the HFA. Since the representation of the problem in the SFDRR largely overlaps with that of the HFA, we focus later on what has changed in this representation within the new framework, and its effects on the appointed space for action as well as responsible actors. We conclude our analysis by presenting some perspectives that are de-emphasized or excluded within the strategy.

\section{The Hyogo Framework for Action}

\section{$\underline{\text { Representations of the problem and causal logics }}$}

The HFA puts special emphasis on managing disaster risks. Disaster risks are depicted as consequences of the interaction of hazards with vulnerabilities of a physical, social, economic, and environmental character (UNISDR, 2005, p. 1). The term interaction has profound implications for the representation of the problem. Hazard is represented as a "potentially damaging physical event, phenomenon, or human activity” (UNISDR, 2005, p. 1) that alone cannot cause a disaster. It is the combination of that triggering agent with vulnerabilities that 
"may cause loss of life or injury, property damage, social and economic disruption, or environmental degradation” (UNISDR, 2005, p. 1). Furthermore, the triggering agent is not understood in terms of natural hazards alone. It may also be the consequence of human activity, for example, technological hazards referring to the "negative side” of science and technology in the creation of new risks (cf. Beck, 2011), or (even) environmental degradation.

Vulnerability is also represented as multicausal, encompassing both physical factors (for example, the proximity of persons and assets to triggering agents) and other social, economic, and environmental characteristics that increase susceptibility, and thereby, the consequences of hazards (UNISDR, 2005, p. 1). A wide set of factors that eventually increase vulnerabilities is included in the framework, leaving space for multiple causal assumptions. Among those mentioned are technological and socio-economic conditions, underdevelopment, and unplanned urbanization, as well as changing demographics, environmental degradation, climate variability, and climate change. These factors can be ascribed to harmful side effects of policy (unknown or ignored), carelessness, or even negligence, and thus their causes may be both inadvertent and intentional. Other factors such as development within high-risk zones or competition for scarce resources could also point at intentional causes related to negligence, and to economic wealth.

Thus, disasters are represented as complex causal systems, which could provide the grounds for various directions for action and responsibilities. Their broad scope means they are entangled with various discourses, such as environmental, development, or economic. Not only are disasters represented as complex causal systems, but these causal connections also may take multiple forms (depending on the nature of the triggering agent, the vulnerability factors, and their interaction). Thus, this broad representation of disasters makes responsibility contingent, diffused, or dispersed into other policy fields. If the causes of a problem are multiple, interrelated, and highly contingent, the appointed space for action is limited to some general form of preparedness and response. Still, these complex causal systems involve multiple responsibilities that could be implicated. On the one hand, inadvertent (or even possibly intentional) causes may be ascribed to uninformed policymaking, negligence of politicians, or malpractice of public servants. On the other hand, non-intentional causes, mainly related to lack of knowledge or carelessness, seem to be attributed to non-state stakeholders.

$\underline{\text { Space for Action }}$ 
In accordance with the problem representation identified in the HFA, which is dominantly centered on human action as shaping vulnerabilities, and in some cases, creating hazards, the strategy aims at managing risks and creating resilient communities. In that sense it takes a proactive approach to disaster management. However, the priorities for action and related measures prescribed in the framework (see Appendix 1, UNISDR, 2005, pp. 6-12) emphasize proactivity mainly through the managing of existing risks and reducing of only some underlying risk factors. The main space for action, as represented in the strategy, is overall preparedness for an effective response. The strategy is oriented at building legal, institutional, technical, and managerial capacities at the national level, using knowledge and technical innovations to gather, compile, compare, and disseminate relevant knowledge on hazards and vulnerabilities (mostly on top-down bases), and raising community awareness. Meanwhile, the HFA accounts for a more reactive approach regarding the prevention of new risks, and achievement of sustainable reconstruction in post-disaster recovery. New risks are only mentioned in passing as underlying risk factors, as is sustainable reconstruction in relation to the integration of risk reduction into development policies.

We argue that the proactivity represented in the documents is a limited proactivity. It is limited because many developments that in the strategy are represented as increasing vulnerabilities are not within the space for action, among others, changing demographics, technological and some socio-economic conditions, and underdevelopment and climate change. Thus, the strategy is primarily directed at assessing and controlling existing risks and some vulnerabilities, while the prevention of new risks and the reduction of many factors that create and increase vulnerabilities are beyond the space for action.

As a means to enhance preparedness, the HFA expresses a demand for specification and contextualization of factors influencing vulnerability. This trajectory for action indicates inadvertent causes (such as the negative side of policies, and ignorance or carelessness) that can be tackled at the national and local levels, for example, by gaining more knowledge on disaster risks and vulnerability, developing new policies on the basis of this information, improving early warning systems and land-use planning, and enhancing education and training for raised awareness. Thus, the appointed space for action is at the national and local levels, and more particularly, in the management of risks. Disaster management is represented as a technical/scientific challenge due to the strong emphasis put on science-based methodologies and evidence-based policymaking, which indicates that a scientific discourse is dominant within the field (cf. Hollis, 2014, p. 352). The understanding of disaster risks, and 
even vulnerabilities, is represented as a product of research practices, information, and (transfer of) available technology (cf. Feindt \& Oels, 2005, p. 162, on the environment).

\section{$\underline{\text { Appointed actors }}$}

The priorities for action contained in the HFA are mainly directed at state governments (these are also the ones that were to agree to the strategy), in terms of the management of disaster risks and reducing vulnerabilities at national and local levels. However, their role as members of the international community is appointed, though in less detail, not only with regard to the provision of international cooperation to build resilience in less developed countries but also indirectly concerning their involvement in international and regional organizations.

Whereas the HFA points out that managing disasters is a shared responsibility of governments and relevant stakeholders, who they are and which responsibilities they have are not extensively endorsed by the strategy. The civil society, including volunteers and communitybased organizations, the scientific community, and the private sector, are put forth as vital in supporting the implementation of disaster risk reduction at all levels (UNISDR, 2005, p. 13). The private sector is mainly encouraged to put greater emphasis on, and allocate resources to, pre-disaster activities such as risk assessments and early warning systems (UNISDR, 2005, p. 11). Public-private partnerships are also taken to increase the engagement of the private sector in disaster risk reduction activities (UNISDR, 2005, p. 11).

\section{The Sendai Framework for Action}

\section{Representations of the problem and causal logics}

The definitions of hazard and vulnerability persist in the SFDRR. The main focus remains on human activity as determinant of the creation of risks and development of vulnerabilities. However, the new framework puts added emphasis on the creation of new risks with significant impact (i.e., economic, social, health, cultural, and environmental), especially at the local and community levels, in the short, medium, and long term (UNISDR 2015a, p. 10). Its representation of the problem is wider and more detailed than its predecessor's, including 
"risk of small-scale and large-scale, frequent and infrequent, sudden and slow-onset disasters caused by natural or man-made hazards, as well as related environmental, technological and biological hazards and risks” (UNISDR 2015a, p. 11).

\section{Space for Action}

To successfully manage existing disaster risks and prevent the creation of new, the priorities for action center the attention on knowledge of hazards and risks (including vulnerability, capacity, and exposure), open exchange of non-sensitive information, and enhanced risk governance through managerial and institutional mechanisms, as well as empowerment of relevant stakeholders at the national and local levels. Thus, the SFDRR underscores the urge to monitor, assess, and understand disaster risks, and the value of risk-informed decisionmaking. It thereby reproduces the scientific/managerial discourse represented in the HFA. The need for contextualization is also put forth in the SFDRR, such as periodical assessment of disaster risks in relation to national conditions and the impacts of national heritage (UNISDR, 2015a: 14), as well as the need to use of traditional, indigenous, and local knowledge and practices as complementary to scientific knowledge (UNISDR, 2015a, p. 15). The SFDRR also adds a point regarding investment in DRR measures (both public and private), and "building back better" in the reconstruction phase (see Appendix 1, UNISDR 2015a, pp. 1422).

The SFDRR's trajectory for action reflects a more proactive strategy where measures are more clearly directed to the different phases of the disaster cycle, that is, before, during, and after the event. It involves anticipation, preparedness, and the integration of DRR in recovery, which is supposed to enable sustainable development. However, it is still a limited proactivity. The reduction of underlying causes of vulnerability no longer has an assigned priority in the SFDRR. Instead, the drivers that cause disaster risk are integrated, in a limited manner, into the other priorities for action, thus losing the emphasis on this point. In this sense it could be argued that the SFDRR represents a step back from the HFA.

\section{$\underline{\text { Appointed actors }}$}

The appointed responsibilities at the government level remain, requiring "the full engagement of all the state institutions of an executive and legislative nature at national and local levels" (UNISDR, 2015a, p. 13). However, the SFDRR also urges “a clear articulation of responsibilities across public and private stakeholders, including business and academia, to 
ensure mutual outreach, partnership, complementarity in roles and accountability and followup” (UNISDR, 2015a, p. 19). The "role of governments" is changed to the "role of stakeholders,” thereby allowing for a broader representation of key actors. The role appropriated for private sector actors has been developed in the SFDRR and includes investment informed by disaster risk, and participation in development of normative frameworks (UNISDR, 2015a, p. 23). However, while the SFDRR includes more explicitly the business sector among the relevant stakeholders, for example, stressing the need for them to include disaster reduction in their management policies (UNISDR, 2015a, p. 11), the responsibility of this sector is not appointed by the framework. Consequently, the broader set of stakeholders does not translate to specifically appointed responsibilities; on the contrary, the broad inclusion supports the diffusion of responsibility that the representation of the “complex causal system” laid the ground for. Still, the SFDRR raises more explicitly the importance of increased competence and accountability. It thus presumes (or at least expects) some degree of relevant knowledge among these stakeholders and that they also will be accountable.

\section{De-emphasized or excluded perspectives}

The problem representation within this strategy has implications not only for the space for action and appointed actors, but also for what remains de-emphasized or silenced. The frameworks do to a large extent represent what we have called the holistic paradigm. Meanwhile, the more structural and systemic understanding of vulnerabilities represented by the vulnerability paradigm is silenced. These limitations take different expressions in the representation.

First, in both frameworks there is an emphasis on national and local contexts and action, whereby the strategy de-emphasizes the processes that are not controllable at this level, as, for example, social structures of inequalities that reproduce vulnerabilities. Global interdependence and power relations can contribute to underdevelopment, corruption, and economic crisis, and thus, DRR measures may not be prioritized. Furthermore, the business sector may settle their manufacturing plants in developing countries, contributing to the externalization of risk and environmental effects. 
Second, the strategy identifies disaster-prone developing countries (UNISDR, 2005, p. 5) and also middle-income countries facing specific challenges (UNISDR, 2015a, p. 10) as victims (giving special emphasis to African states as particularly vulnerable). However, there is no problematization of structural power dimensions that could have led to this condition. As an example, only the "positive side” of global interdependence is emphasized, that is, concerted international cooperation, which is assumed to be "required to stimulate and contribute to developing knowledge, capacities and motivation needed for disaster risk reduction at all levels” (UNISDR, 2005, p. 4), “in particular for developing countries” (UNISDR, 2015a, p. 14). This has been argued to be a representation based on inherent paternalism nestled within the humanitarian imperative (Hollis, 2014, pp. 350-51).

Third, whereas the predominant concern with technological and managerial solutions represents a way to control and anticipate disasters (thus, assuming proactivity), it also eclipses the need for change in the social structures and human behavior that create disaster risks. Furthermore, the scientific discourse identified within the strategy may also risk overrunning local knowledge and life experiences (cf. Jasanoff, 2010). While the importance of indigenous and local knowledge and practices has recently been acknowledged in the SFDRR, it risks being overshadowed by the strong focus on knowledge dissemination and technical innovation.

Fourth, the power dimension that was at the heart of the vulnerability paradigm is lost in this representation. It relates both to global economic dimensions and structures already mentioned, and in a more local context, to why people take certain risks, such as living in exposed areas, in ill-constructed housing and with inadequate insurance. Regarding appointed actors, there is no problematization of the responsibilities concerning non-state actors in relation to those global processes. The liability of economic interests and the role of market mechanisms in the creation of risks are neglected. However, investment and development activities are not risk-neutral (cf. O’Brien et al., 2006). Seventy to eighty percent of total investment is decided by private businesses (UNISDR, 2015b, p. 2), giving them a strong influence over how much risk is accumulated. This representation de-emphasizes, once again, inadvertent and even intended causes that could be the result of carelessness or recklessness within this sector.

Last, the emphasis on systemic change that was present in the vulnerability paradigm is excluded from the UN strategies. The actions proposed by the frameworks tend to dismiss 
large system change. Though there are references to "unsustainable” development or climate variability, which arguably demand systemic change, these issues remain within the scope of other UN institutions. Apart from the more explicit acknowledgment of the urge of planning compatibility among them all, no main improvement has been shown so far in this matter (see also O’Brien et al., 2006, p. 69; Mercer, 2010; Pearson \& Pelling, 2015). A deeper problematization of structurally rooted vulnerability would have assumed other complexcausal stories where responsibility and blame could have been assigned. However, since global inequalities have shown to be immensely difficult to counter, such a focus could have limited the possible accomplishments of the policies. Nevertheless, it is important to point to the exclusion of these perspectives, since they could have laid ground for a more radical proactivity.

\section{Conclusions}

In this paper we have explored how disasters are constructed as a policy problem within the UN global strategy for disaster risk reduction. We have addressed the following questions: (1) What kind of problem are disasters represented to be within these frameworks? (2) What is the effect of the causal assumptions that underlie this representation, in terms of appointed space for action and responsible actors? (3) What is excluded from the representation? We show that the problem in focus is not hazards but disaster risks, which are represented as multicausal systems that encompass a wide range of triggering agents (including human activities) and vulnerabilities. The focus on risks rather that events, together with the highly contingent multicausal system, diffuses responsibilities and excludes blame. The space for action is directed at gathering and disseminating information and knowledge concerning local contexts as well as technical and social innovation, in order to better manage risks and improve preparedness. The appointed key actors are national and local governments. There is an emphasis on proactivity; however, we argue that this proactivity is limited, since the space for action is directed at managing risks rather than treating underlying structural causes and thereby attempting to alter the situation and promote a more radical proactivity. The strategies aim to mitigate the effects of vulnerabilities at the local or national level, rather than addressing structural global processes that render people vulnerable, preeminently-though not only - in less developed countries (e.g., regarding the deterioration in not only the terms of trade but also environmental effects). 
By elaborating on how disasters are problematized in the global strategy, and what the implications of this representation are, we contribute to the debate in different ways. In relating the policies to the different representations of disasters in the academic literature, we show that the global policies largely represent the holistic view. Hence, this view is not only represented in the academic debate; it is also dominant within the policy realm. This finding supports our consideration of the holistic view as an emerging "paradigm.” However, we also show that the holism of this view is limited. This 'paradigm' should be understood in relation to the former. The risk managerial focus of the current UN strategy should be seen in light of the difficulties that the proponents of the vulnerability paradigm faced in altering the structures they challenged. In short, this approach is more manageable since it deemphasizes transnational power and interest conflicts.

The strategy seeks to achieve a highly ambitious goal, and the HFA has shown progress in this endeavor. Still, there is much work to be done. Local governments face challenges that fall outside the frameworks, for example, the need for fundamental change in social structures and habits that create disaster risks. By making visible what is excluded or not properly problematized in this representation, we point to the complexity of the task and show where its limitations lie. Assessing risks, fostering partnerships, enhancing preparedness, and making people more aware of risks is a good start, but is not sufficient to cope with disasters. Silence that, for example, plays down the liability of economic interests in the creation of risks, or the significance of power relations when it comes to choosing the measure to invest in (e.g., the construction of a barrier vis-à-vis the relocation of vulnerable populations), limit the scope for action that governmental authorities actually have to reduce disaster risks.

How can we understand the closeness between the policy discourse and the scientific discourse? The domination of the holistic perspective could be interpreted as a rationalist achievement where the knowledge produced by science, or the academic world, has come to influence policy on a global scale. However, the influences in the other direction, from policy to science, should not be underestimated. Policies do not only shape the world being studied, they may also involve research funding, and in that respect, influence the directions taken within the academic world. Science and policy are co-producers of global discourses (Jasanoff, 2004). We see the International Strategy for Disaster Risk Reduction as an articulation of global norms. Since the effect of global economic structures on power relations, development, and environmental challenges remains unproblematized in the 
strategy, the framework serves to uphold, rather than to challenge, global norms and structures.

\section{References}

Bacchi, C. (2000). Policy as Discourse: What does it mean? Where does it get us? Discourse, 21(1), 45-57.

Bacchi, C. L. (2008). Women, Policy and Politics: The Construction of Policy Problems. London: Sage.

Bacchi, C. (2012). Why Study Problematizations? Making Politics Visible. Open Journal of Political Science, 2(01), 1-8.

Bacchi, C. (2015). Problematizations in Alcohol Policy: WHO’s “Alcohol Problems.” Contemporary Drugs Problems 1-8.

Birkmann, J. (2006). Measuring Vulnerability to Promote Disaster-Resilient Societies: Conceptual Frameworks and Definitions. In Birkmann, J. (Ed.), Measuring Vulnerability to Natural Hazards: Towards Disaster Resilient Societies. Tokyo: United Nations University Press, pp. 9-54.

Birkmann, J., and Wisner, B. (2006). Measuring the Un-measurable: The Challenge of Vulnerability. Studies of the University: "Research, Counsel, Education.” Publication Series of UNU-EHS 5. Bonn: UNU Institute for Environment and Human Security (UNU-EHS).

Botzen, W. and Van den Bergh, J. (2009). Managing Natural Disaster Risk in a Changing Climate. Environmental Hazards, 8(3), 209-25.

Burton, I., and Kates, R. W. (1964). Slaying the Malthusian Dragon: A Review. Worcester, MA: Clark University.

Collins, A. E. (2009). Disaster and Development. New York, NY: Routledge.

Comfort, L., Wisner, B., Cutter, S., Pulwarty, R., Hewitt, K., Oliver-Smith, A., . . . Krimgold, F. (1999). Reframing Disaster Policy: The Global Evolution of Vulnerable Communities. Environmental Hazards, 1, 39-44. 
Dahl, H. M. (2012). Tavshed som magt og afmagt. Antropologi, 33(66), 3-16.

Dodds, G. G. (2015). “This Was No Act of God:” Disaster, Causality, and Politics. Risk, Hazards \& Crisis in Public Policy, 6(1), 44-68.

Djalante, R., and Thomalla, F. (2011). Community Resilience to Natural Hazards and Climate Change Impacts: A Review of Definitions and Operational Frameworks. Asian Journal of Environment \& Disaster Management, 3(3), 339-55.

Djalante, R., Thomalla, F., Sinapoy, M. S., and Carnegie, M. (2012). Building Resilience to Natural Hazards in Indonesia: Progress and Challenges in Implementing the Hyogo Framework for Action. Natural Hazards, 62(3), 779-803.

Enia, J. (2013). The Spotty Record of the Hyogo Framework for Action: Understanding the Incentives of Natural Disaster Politics and Policy Making. The Social Science Journal, 50(2), 213-24.

Fischer, F. (2003). Reframing Public Policy: Discursive Politics and Deliberative Practices. Oxford: Oxford University Press.

Feindt, P., and Oels A. (2005). Does Discourse Matter? Discourse Analysis in Environmental Policy Making. Journal of Environmental Policy \& Planning, 7(3), 161-73.

Furedi, F. (2007). The Changing Meaning of Disaster. Area, 39(4), 482-89.

Gaillard, J. C. (2007). Resilience of Traditional Societies in Facing Natural Hazards. Disaster Prevention and Management: An International Journal, 16(4), 522-44.

Gaillard, J. C. (2010). Vulnerability, Capacity and Resilience: Perspectives for Climate and Development Policies. Journal of International Development, 22(2), 218-32.

Geis, D. (2000). By Design: The Disaster-Resistant and Quality-of-Life Community. Natural Hazards Review, 1(3), 151-60.

Gregory, D., Johnson, R., Pratt, G., Watts, M. J., and Whatmore, S. (Eds.). (2009). The Dictionary of Human Geography. Hoboken, NJ: Wiley-Blackwell.

Hajer, M. A. (1995). The Politics of Environmental Discourse: Ecological Modernization and the Policy Process. Oxford: Clarendon Press. 
Hajer, M. A., and Laws, D. (2006). Ordering Through Discourse. In M. Moran, M. Rein, and R. E. Goodin (Eds.), The Oxford Handbook of Public Policy (pp. 251-268). New York: Oxford University Press.

Hannigan, J. (2012). Disasters Without Borders: The International Politics of Natural Disasters. Cambridge: Polity Press.

Hoffman, S. and Oliver-Smith, A. (1999). Anthropology and the Angry Earth: An Overview. In Oliver-Smith, A., and S. M. Hoffman (Eds.), The Angry Earth: Disaster in Anthropological Perspective. London: Routledge, pp. 1-16.

Hollis, S. (2014). Competing and Complimentary Discourses in Global Disaster Risk Management. Risk, Hazards \& Crisis in Public Policy, 5(3), 342-63.

Jasanoff, S. (Ed.). (2004). States of Knowledge: The co-production of science and the social order. London: Routledge.

Jasanoff, S. (2010). A New Climate for Society. Theory, Culture \& Society, 27(2-3), 233-53.

Jensen, S. J., Feldmann-Jensen, S., Johnston, D. M., and Brown, N. A. (2015). The Emergence of a Globalized System for Disaster Risk Management and Challenges for Appropriate Governance. International Journal of Disaster Risk Science, 6(1), 87-93.

Kelman, I. (2015). Climate Change and the Sendai Framework for Disaster Risk Reduction. International Journal of Disaster Risk Science, 6(2), 117-27.

Konoorayar, K. V. (2006). Disasters: Global Response to the Challenges. AALCO Quarterly Bulletin, 2(4): 359-84.

Latour, B. (2004). Politics of Nature: How to Bring the Sciences into Democracy. Cambridge, MA: Harvard University Press.

Lövbrand, E., Beck, S., Chilvers, J., Forsyth, T., Hedrén, J., Hulme, M., . . Vasileiadou, E. (2015). Who Speaks for the Future of Earth? How Critical Social Science Can Extend the Conversation on the Anthropocene. Global Environmental Change, 32, 211-18.

Manyena, S. B., Mavhura, E., Muzenda, C., and Mabaso, E. (2013). Disaster Risk Reduction Legislations: Is There a Move from Events to Processes? Global Environmental Change 23(6), 1786-94. 
Matsuoka, Y., Sharma, A., and Shaw, R. (2009). Hyogo Framework for Action and Urban Risk Reduction in Asia. Urban Risk Reduction: An Asian Perspective, 1, 77.

Matsuoka, Y., and Shaw, R. (2011). Linking Resilience Planning to Hyogo Framework for Action in Cities. Climate and Disaster Resilience in Cities. Community, Environment and Disaster Risk Management, 6, 129-47.

Matsuoka, Y., and Shaw, R. (2012). Hyogo Framework for Action as an Assessment Tool of Risk Reduction: Philippines National Progress and Makati City. Risk, Hazards \& Crisis in Public Policy, 3(4), 18-39.

McEntire, D. A. (1998). Balancing International Approaches to Disaster: Rethinking Prevention Instead of Relief. Australian Journal of Emergency Management, 13(2), $50-55$.

McEntire, D. A. (2001). Triggering Agents, Vulnerabilities and Disaster Reduction: Towards a Holistic Paradigm. Disaster Prevention and Management, 10(3), 189-96.

McEntire, D. A., Fuller, C., Johnston, C. W., Weber, R. (2002). A Comparison of Disaster Paradigms: The Search for a Holistic Policy Guide. Public Administration Review, 62(3), 267-81.

Mercer, J. (2010). Disaster Risk Reduction or Climate Change Adaptation: Are We Reinventing the Wheel? Journal of International Development, 22(2), 247-64.

O’Brien, G., O’Keefe, P., Rose, J., and Wisner, B. (2006). Climate Change and Disaster Management. Disasters 30(1), 64-80.

Oliver-Smith, A. (1996). Anthropological Research on Hazards and Disasters. Annual Review of Anthropology, 25, 303-28.

Oliver-Smith, A. (1999). “What Is a Disaster?” Anthropological Perspectives on a Persistent Question. In A. Oliver-Smith and S. M. Hoffman (Eds.), The Angry Earth: Disaster in Anthropological Perspective. London: Routledge, pp. 18-34.

Olowu, D. (2010). “The Hyogo Framework for Action and Its Implications for Disaster Management and Reduction in Africa.” Journal of Disaster Risk Studies, 3(1), 30319. 
Palliyaguru, R., Amaratunga, D., and Baldry, D. (2014). Constructing a Holistic Approach to Disaster Risk Reduction: The Significance of Focusing on Vulnerability Reduction. Disasters, 38(1), 45-61.

Pearson, L. and Pelling, M. (2015). The UN Sendai Framework for Disaster Risk Reduction 2015-2030: Negotiation Process and Prospects for Science and Practice. Journal of Extreme Events, 2(01), 1571001-1-1571001-12.

Pizzo, B. (2015). Problematizing Resilience: Implications for Planning Theory and Practice. Cities, 43, 133-40.

Quarantelli, E. L. (2000). Disaster Planning, Emergency Management and Civil Protection: The Historical Development of Organized Efforts to Plan for and to Respond to Disasters. University of Delaware Disaster Research Center, preliminary paper No. 301.

Rittel, H. W. J., and Webber, M. M. (1973). Dilemmas in a General Theory of Planning. Policy Sciences, 4, 155-69.

Schipper, L., and Pelling, M. (2006). Disaster Risk, Climate Change and International Development: Scope for, and Challenges to, Integration. Disasters, 30(1), 19-38.

Schön, D. A., and Rein, M. (1994). Frame Reflection: Toward the Resolution of Intractable Policy Controversies. New York, NY: Basic Books.

Stone, D. A. (2012). Policy Paradox: The Art of Political Decision Making (3rd ed.). New York, NY: Norton.

Stanganelli, M. (2008). A New Pattern of Risk Management: The Hyogo Framework for Action and Italian Practise. Socio-Economic Planning Sciences, 42(2), 92-111.

Thomalla, F., Downing, T., Spanger-Siegfried, E., Han, G., and Rockström, J. (2006). Reducing Hazard Vulnerability: Towards a Common Approach Between Disaster Risk Reduction and Climate Adaptation. Disasters, 30(1), 39-48.

UNISDR. (2005). Hyogo Framework for Action 2005-2015: Building the Resilience of Nations and Communities to Disasters. Geneva: United Nations International Strategy for Disaster Reduction. 
UNISDR. (2015a). Sendai Framework for Disaster Risk Reduction 2015-2030. Geneva: United Nations International Strategy for Disaster Reduction.

UNISDR. (2015b). Coherence and Mutual Reinforcement Between the Sendai Framework for Disaster Risk Reduction 2015-2030 and International Agreements for Development and Climate Action. Geneva: United Nations International Strategy for Disaster Reduction.

Vink, K., and Takeuchi, K. (2013). International Comparison of Measures Taken for Vulnerable People in Disaster Risk Management Laws. International Journal of Disaster Risk Reduction, 4, 63-70.

Weichselgartner, J., and Pigeon, P. (2015). The Role of Knowledge in Disaster Risk Reduction. International Journal of Disaster Risk Science, 6(2), 107-16.

Wisner, B., Blaikie, P., Cannon, T., and Davis, I. (2004). At Risk: Natural Hazards, People’s Vulnerability and Disasters (2nd ed.). London: Routledge.

Yanow, D. (1992). Silences in Public Policy Discourse: Organizational and Policy Myths. Journal of Public Administration Research and Theory, 2(4), 399-423.

Yanow, D. (1996). How Does a Policy Mean? Interpreting Policy and Organizational Actions. Washington, DC: Georgetown University Press. 